\title{
Bretschneider, Falk, Gefangene Gesellschaft. Eine Geschichte der Einsperrung in Sachsen im 18. und 19. Jahrhundert
}

\section{Marco Cicchini}

\section{OpenEdition}

\section{Journals}

Édition électronique

URL : http://journals.openedition.org/ifha/2110

DOI : 10.4000/ifha. 2110

ISSN : 2198-8943

\section{Éditeur}

IFRA - Institut franco-allemand (sciences historiques et sociales)

Référence électronique

Marco Cicchini, «Bretschneider, Falk, Gefangene Gesellschaft. Eine Geschichte der Einsperrung in Sachsen im 18. und 19. Jahrhundert », Revue de I'IFHA [En ligne], Date de recension, mis en ligne le 01 janvier 2010, consulté le 22 septembre 2020. URL : http://journals.openedition.org/ifha/2110 ; DOI https://doi.org/10.4000/ifha. 2110

Ce document a été généré automatiquement le 22 septembre 2020.

(CIFHA 


\title{
Bretschneider, Falk, Gefangene Gesellschaft. Eine Geschichte der Einsperrung in Sachsen im 18. und 19. Jahrhundert
}

\author{
Marco Cicchini
}

1 Version remaniée d'une thèse de doctorat achevée en 2005, codirigée par Jacques Revel et Gerd Schwerhoff, ce livre ambitieux et imposant enrichit significativement l'histoire des prisons en Europe, aux XVIIIe et XIXe siècles. Plutôt que de privilégier le problème des économies punitives et des intentions qui les sous-tendent, F.B. propose une histoire de l'enfermement à partir des lieux, des acteurs, des activités et des relations entre individus et groupes sociaux. La riche série des sources administratives et des registres d'écrous de l'ancien duché de Saxe lui permet de croiser une histoire sociale minutieuse et informative (plus de 50 tableaux et graphiques) avec une approche théorique particulièrement bien maîtrisée (avant tout Foucault, Goffman, Elias). Dixneuf chapitres, plutôt factuels et chronologiques, fournissent la matière première de l'analyse. Deux chapitres introductifs et les conclusions sont consacrés à la présentation du triple déplacement historiographique que le livre entend opérer ou confirmer, à propos de la chronologie, du statut de la discipline et de la notion d'institution dans l'émergence de la société enfermée.

2 À la différence d'une tradition historiographique bien établie qui fait de l'année 1800 le marqueur temporel de l'essor de la prison comme institution pénale, F.B. atténue fortement l'idée d'un changement brutal. L'enfermement punitif fait par exemple partie de l'arsenal ancien des ordonnances de police. De plus, l'identité des reclus, comme le montre l'exemple de la maison de discipline de Waldheim (créée en 1716), se modifie déjà au XVIIIe siècle. Alors que le modèle d'une institution multifonctionnelle prédomine jusque vers 1750 (où se mêlent, annuellement, quelques centaines d'hommes et de femmes, pauvres, orphelins, malades, insensés, prostituées, vagabonds, délinquants et criminels), l'enfermement punitif devient prépondérant à partir de 1770 
(p. 243). Enfin, malgré la multiplication des lieux d'enfermement et un processus de différenciation institutionnelle, les anciennes pratiques d'enfermement perdurent même à l'ère des réformes libérales du XIXe siècle.

3 Fidèle aux leçons du "tournant pragmatique » des années 1980, et à la manière de Sabina Loriga à propos des armées piémontaises du XVIIIe siècle, F.B. insiste ensuite sur la complexité des relations sociales qu'entretiennent les divers acteurs de l'enfermement. La volonté disciplinaire est loin d'être souveraine et ne provient nullement d'un pouvoir homogène, comme le montre l'analyse des relais institutionnels des autorités (Hausverwalter, soldats). Si les châtiments corporels font partie du quotidien, les " niches " de liberté, dans le temps et dans l'espace, sont possibles. De cela est particulièrement exemplaire le « commerce charnel » qui sévit à Waldheim alors que les cadres de la mixité sexuelle ne sont véritablement définis qu’à partir du début du XIXe siècle.

4 Enfin, l'auteur note que les institutions d'enfermement, entre XVIIIe et XIXe siècle, sont à replacer dans un espace social plus large dont elles ne sont séparées que par des frontières poreuses. L'évolution de la population recluse et les travaux auxquels celle-ci est astreinte sont, par exemple, considérablement affectés par la conjoncture économique et politique du duché. De plus, malgré les contraintes vécues, les prisonniers sont aussi à considérer comme des acteurs du devenir institutionnel, comme le montre la révolte carcérale de 1825 à la maison de discipline de Zwickau, finement restituée, qui aboutit à la destitution de l'administrateur pour exercice abusif de l'autorité.

5 Si la matière de l'ouvrage est très dense, un effort de synthèse supplémentaire aurait sans doute fait perdre des données essentielles, alimentées, rappelons-le, par deux siècles d'archives. Gageons donc que ce livre saura ouvrir de nouveaux chantiers sur l'histoire sociale de l'enfermement : comme le souligne Jacques Revel dans la préface, il s'agit moins ici d'un cas isolé que d'un laboratoire qui, comme tel, peut-être répliqué pour les besoins collectifs de la connaissance historienne.

6 Marco Cicchini (Université de Genève) 